\title{
THE DEATH OF DARWIN?
}

In 1957 John Greene wrote The Death of Adam. In recent years he has seemed to want to prove the death of Darwin, as indicated by the preceding essay and other recent writings. Is there any substance to Greene's endeavor to demonstrate the obsolescence of Darwin's theories and ideas? A Darwinian reading Greene's arguments is overcome by a feeling of frustration. There we have labored for the last 50 years to make Darwin's thought better known, and have documented how brilliantly Darwin has overcome all the objections raised against his work so that we are now « closer to Darwin's basic ideas than biologists have ever been since 1859 ». It is discouraging to find out how completely Greene ignores this argumentation and instead arrives at conclusions that reveal quite conclusively how little he understands Darwin's thought.

Ghiselin, myself, and many of the recent Darwin scholars have emphasized what a revolutionary innovator in philosophy Darwin was. Without referring to any of that literature, Greene treats Darwin as a man hopelessly entangled in the now obsolete concepts of the GalileanCartesian philosophy of overything in nature being due to matter in motion. He altogether fails to mention that Darwin has liberated us from that philosophy which is so totally unsuitable for biology. Darwin's emphasis on variation, populations, chance, and pluralism started a new era in the philosophy of nature, an insight that can no longer be ignored even though there are still some philosophers who only read each other's writings or the literature of the physical sciences. How little Greene understands Darwin's thought is well documented by the fact that he always brackets him together with Spencer, two writers whose ideas had remarkably little in common, as has been demonstrated by recent writers.

Revue de synthèse : IVe $\mathrm{S} . \mathrm{N}^{\circ} 3$, juillet-septembre 1986. 
Even though Darwin, in the fashion of his period, talked a good deal about laws, it is quite evident, and Greene also recognizes this, that they were not the God-given laws of the deists but rather simple facts or what Greene calls processes. Since Darwin did not believe in fixed laws, natural selection for him was a statistical process. This went over very poorly with the deterministic physicists, and this is why Herschel maligned natural selection as the law of the higgledy-piggledy. To describe Darwin's entirely new way of interpreting nature as an adherence to the Cartesian matter-in-motion principle is totally misleading.

Greene seems to think that he can document Darwin's uncertainties and inconsistencies particularly well by his treatment of progress. When dealing with progress in the world of life, one must make a clear distinction between the progression in the complexity of types of organisms in the long geological history of the earth, and the teleological interpretation of the causes of such progress. Through the researches of the last 25 years, we now know that life on earth after its origin about 3.5 billion years ago remained extremely simple for about 2 billion years, and that such evolutionary innovations as warm-bloodedness and highly organized central nervous systems are a product of only the last couple of hundred million years. The term evolutionary progress is highly inappropriate when ascribed to teleological or finalistic forces. But both Darwin (Mayr, 1983) and Julian Huxley rejected such a usage. Yet to designate as progress the series of changes from the simplest prokaryote to a large angiosperm tree or a primate, is descriptively legitimate. How else could we designate the successive, innovative acquisitions of photosynthesis, eukaryoty (development of a nucleus), multicellularity (metaphytes, metazoans), diploidy, homeothermy, central nervous systems, and parental care (Mayr, The Growth of Biological Thought. Diversity, Evolution and Inheritance, Cambridge, Mass., The Belknap Press of Harvard University Press, 1982, p. 532) ? Greene finds it impossible to reconcile this evolutionary progression « with the mechanistic view of nature ". Yet, as Darwin said so clearly, the combined forces of competition and natural selection leave no other alternate but either extinction or evolutionary progression. The analogy between evolution and industrial developments is quite legitimate. Why are modern motor cars so strikingly better than those of 75 years ago ? Because all manufacturers constantly experimented with various innovations, while competition through customer demands led to enormous selection pressure. Neither in the automobile industry nor in the world of life do we find any finalistic forces at work, nor any mechanistic determinism. Hence when $J$. Huxley described progressive evolution in figures of 
speech borrowed from the progress of human technology, he did not in the least fall " into an implicit vitalism and teleology and undermined the idea that human beings are part of nature ", as Greene accuses him.

How little Greene understands variational evolution is documented by his statement that there is a conflict between "competitive struggle as the sine qua non of progress in nature and history and admiring the wonderful adaptedness and interdependence of organic beings $»$. But that is of course exactly the core concept of natural selection. Of course an essentialist, and Greene writes like an essentialist, has trouble understanding what consequences the selective survival of certain uniquely different individuals in a large population will have on the genetic endowment of future generations. Incidentally, competition was not quite as strictly a British concept as claimed by Greene. It was well appreciated on the Continent, as documented in the writings of Herder and de Candolle. These authors, however, being essentialists, were unable to use competition as a component in a theory of natural selection.

Greene, the historian, is very much of an externalist, and seems inclined to ascribe all changes in scientific theory to ideological forces. When evolutionists (during the evolutionary synthesis) rejected orthogenesis and neo-Lamarckism, they did so, thinks Greene, because these theories were considered "metaphysical ". A closer look at the literature, however, shows rather clearly that these theories were rejected for three reasons : first, numerous facts were in clear violation of these theories ; and secondly, all efforts to find biological mechanisms that would make orthogenesis or an inheritance of acquired characters possible were unsuccessful ; and thirdly, all the relevant facts could be explained quite readily by natural selection. I found no evidence in the literature that these hypotheses were rejected as being " metaphysical ". They simply did not stand up against a proper scientific analysis.

Greene's failure to understand Darwinian thought is well illustrated by his detailed analysis of the thought of Julian Huxley. In fact he devotes nearly 30 per cent of his essay to an analysis of these views, particularly as presented in Evolution: the Modern Synthesis (1943). Actually, Huxley's views although upholding the main thesis of Darwin, were not at all typical of those of the architects of the synthesis. Huxley's strong support of evolutionary progress, his definition of progress by criteria that would establish Man as the highest, best adapted organism, his claim that evolution at the species level was ultimately irrelevant as far as evolutionary trends are concerned, and several other claims made by Huxley were criticized by Simpson, Dobzhansky, Mayr, and other evolutionists long before Greene. In order to evaluate J. Huxley, one must remember that his background was in experimental 
biology and that he never worked in population biology or systematics. What he said on these subjects was derived from the literature and did not always reflect the best contemporary thinking. It must also be remembered that, like his grandfather, Huxley excelled in popular presentation and that he lectured far and wide to the general pubiic. His concern for these audiences clearly colored his writings.

In many of his objections against Darwinism, Greene argues like a teleologist, with this word being used in its classical sense, in the same sense as it was by Darwin's adversaries Sedgwick and K. E. von Baer. Indeed his teleology seems to have the same ideological basis. From all of his writings it is evident that Greene is a devout Christian. Apparently he cannot adopt Darwinism because he sees God's hand in everything in nature. The evolutionary progression from the simplest prokaryotes to Man is for him clear evidence of the workings of the mind of the Creator. Any attempt at a purely materialistic explanation would cause an insoluble conflict.

Evidently Greene is unable to see any difference between teleonomic and teleological. That organisms are entirely different systems from inanimate matter is something Greene evidently fails to understand. The fact that the genetic program is coded information, that it contains instructions, and that it behaves in most ways very much like a program in a computer, somehow seems to make no sense to Greene. That it was convenient for the evolutionist to take over some of the computer terminology in view of the far-reaching equivalence of the two systems is for Greene simply a " highly anthropomorphic projecting onto a nonhuman process the technological aims and terminology of human engineering ". Aristotle more than 2000 years ago already understood remarkably well that a program of instruction is needed for the development of an egg, as recently shown by Aristotle scholars, and molecular genetics has discovered the nature of this program. To do away with these developments as " anthropomorphism " is a remarkably ingenuous solution.

How simplistic Greene's understanding of evolution is, is well expressed by his question : "How, then, was he [J. Huxley] to avoid the scylla of finalism and vitalism without steering into the Charybdis of a mechanical determinism that reduced biology to physics and chemistry ? " As if Darwin had not found in natural selection exactly the way by which the stated dilemma can be avoided.

In a curious argument which, frankly, I was quite unable to follow, Greene accuses the Darwinians of having brought telos into the world and to have placed " anthropocentrism once more in the driver's seat ". He ridicules the fear expressed by J. Huxley that " the fate not only 
of mankind but also of life on the planet Earth... was now seen to depend... on human decisions for good or ill ". Has Greene never heard of the heart-rending destruction of the tropical forests and the inevitable extermination of quite literally millions of species of animals and plants, has he never heard of the thousands of sterile acid lakes, or of the dying of a large part of the European forests, or of the desertification of the Sahel and other savannah regions aggravated by overgrazing, of the greenhouse effect, not to mention the threatening nuclear winter ? It is a real mystery to me how anyone in this day and age can still ignore the fatal impact of human decisions on the life occupying the planet Earth.

Philosophers of science have always emphasized that all major research traditions (Kuhn's paradigms) are a mixture of old and new, with inconsistencies and even outright contradictions as well as unopened black boxes. Darwin's paradigm was no exception, and evolutionary biologists have worked for the last 125 years to explore the black boxes and to remove inconsistencies. Would it be justified to claim that this revisionary process has led to a refutation of Darwinism, or is it rather true that it merely resulted in its clarification and purification? Greene insists on the former, we evolutionists on the second alternative. The only way to decide who is right is to look at the set of theories of which Darwin's paradigm is composed, and see whether or not they are still considered valid.

Was Darwin right about proclaiming evolution ? Certainly, except that he called it a theory, while the modern biologist has such overwhelming evidence for evolution that he simply considers it a fact, as much of a fact as that the earth moves around the sun rather than the reverse.

Was Darwin right about common descent ? Certainly. The last link in the chain of evidence was the demonstration by molecular biology that all organisms have the same genetic code. There is a historical unity in the entire living world which cannot help but have a deep meaning for any thinking person and for his feeling toward fellow organisms.

Was Darwin right about the gradualness of evolution? Yes, provided gradualness is properly defined. Darwin opposed typological saltation as well as any speeial creation by the " introduction " of new species in the form of single individuals. We now understand that evolution is a populational process, consisting of the gradual - slow or rapid - genetic reordering of populations. To be sure there is also polyploidy, a process able to produce new species instantaneously, primarily among plants. But this has not led to any macroevolutionary consequences different from populational evolution. All other speciation is populational, even in the theory of punctuated equilbria. 
Finally, what about natural selection ? Darwin realized that selection could not work unless it had unlimited variation at its disposal. But he had no idea where this variation came from. So he thought that use and disuse, and other forms of inheritance of acquired characters, might contribute to the production of variability. We now know that in this he was wrong. He was also wrong in thinking that at least some inheritance was " blending ", that is that it would lead to a complete fusion of paternal and maternal characters. Otherwise, Darwin was remarkably astute. He clearly saw (better than Wallace and most other contemporaries) that there were two kinds of selection such for general viability leading to the maintenance or improvement of adaptedness, and this he called natural selection, and such other selection that leads to greater reproductive success.

Where we differ from Darwin is almost entirely on matters of emphasis. Darwin was fully aware of the probabilistic nature of selection, but the modern evolutionist emphasizes this even more. Chance events play an important role in evolution as it is seen by modern evolutionists. Nor would we be prepared to say that « selection can do anything " (neither did Darwin ever say this). On the contrary, there are very numerous constraints on selection. And appallingly often selection is for various reasons unable to prevent extinction.

How different is this interpretation of the evolutionist from Greene's ultimate conclusions? They are embodied in such sentences as " the concept of nature presupposed by Darwin and his contemporaries was disintegrating ", or "the ideas of nature and science Darwin and his contemporaries took for granted are no longer viable "; in other words, Darwin is dead !

Actually, the basic Darwinian paradigm is as well and as alive today as it was in Darwin's day. Some of the peripheral ones of Darwin's ideas such as an inheritance of acquired characters and blending inheritance, had to be discarded. But this actually only strengthens his theory. All of Darwin's more basic principles are far more firmly established today than they were in Darwin's lifetime.

Greene might answer that he is not interested in technical details of evolutionary biology, but in the more basic conceptual framework that controlled Darwin's thinking. But here also the philosophical revolution brought about by Darwin is more firmly established than ever. What Darwin rebelled against were a number of dominant beliefs of his day. One was the assumption of natural theology that the world had been designed by the Creator and that everything in the world of life was the result of the wise and benign thought of the Creator. How decisively Darwin emancipated himself from this belief of his youth has been 
excellently described by Gillespie (1981). In connection with this Darwin once and for all refuted another dominant belief of his period, that there is an immanent teleology in this world that will lead to ultimate perfection or whatever telos the Creator had in mind. Darwin eliminated any reliance on supernaturalism and provided the explanatory models that made this possible. Equally important was his refutation of essentialism and its replacement by population thinking. It established a new emphasis on variation, on a potential for change, and on the uniqueness of individuals. It was this population thinking that made the theory of natural selection possible. Philosophers have not yet quite caught up with all the consequences of these revolutionary new ideas.

Contrary to Greene's assertions, these most basic ideas are not only still alive, but they are infinitely better established than they were in Darwin's own day. One hundred and twenty-five years of unsuccessful refutations have resulted in an immense strengthening of Darwinism. Whatever attacks on Darwinism are made in our age are made by outsiders, jurists, journalists, etc. The controversies within evolutionary biology about such matters as the occurrence of sympatric speciation, the existence or not of cohesive domains within the genotype, the relative frequency of complete stasis in species, the rate of speciation, and whatever other arguments there are these days, all take place within the framework of Darwinism. The claims of certain outsiders that Darwinism is in the process of being refuted are entirely based on ignorance. To repeat, the basic Darwinian principles are more firmly established than ever. Paraphrasing Mark Twain, we are justified in saying that the news of " the death of Darwin " is greatly exaggerated.

Ernst MAYR, Harvard University. 